15. Seifert AW, Kiama SG, Seifert MG, Goheen JR, Palmer TM, Maden M. Skin shedding and tissue regeneration in African spiny mice (Acomys). Nature. 2012;489:561-5.

16. Puente BN, Kimura W, Muralidhar SA, Moon J, Amatruda JF, Phelps KL, et al. The oxygen-rich postnatal environment induces cardiomyocyte cell-cycle arrest through DNA damage response. Cell. 2014; $157: 565-79$

17. Mills RJ, Titmarsh DM, Koenig X, Parker BL, Ryall JG, Quaife-Ryan GA, et al. Functional screening in human cardiac organoids reveals a metabolic mechanism for cardiomyocyte cell cycle arrest. Proc Natl Acad Sci USA. 2017;114: E8372-81.

18. Nakada Y, Canseco DC, Thet S, Abdisalaam S, Asaithamby A, Santos CX, et al. Hypoxia induces heart regeneration in adult mice. Nature. 2017;541: 222-7.

19. Eschenhagen T, Bolli R, Braun T, Field LJ, Fleischmann BK, Frisen J, et al. Cardiomyocyte regeneration: a consensus statement. Circulation. 2017;136: 680-6.
20. D'Uva G, Aharonov A, Lauriola M, Kain D, Yahalom-Ronen Y, Carvalho S, et al ERBB2 triggers mammalian heart regeneration by promoting cardiomyocyte dedifferentiation and proliferation. Nat Cell Biol. 2015;17:627-38.

21. Leach JP, Heallen T, Zhang M, Rahmani M, Morikawa Y, Hill MC, et al. Hippo pathway deficiency reverses systolic heart failure after infarction. Nature. 2017; 550:260-4.

22. Mohamed TMA, Ang YS, Radzinsky E, Zhou P, Huang Y, Elfenbein A, et al Regulation of cell cycle to stimulate adult cardiomyocyte proliferation and cardiac regeneration. Cell. 2018;173:104-16.e112.

23. Eulalio A, Mano M, Dal Ferro M, Zentilin L, Sinagra G, Zacchigna S, et al. Functional screening identifies miRNAs inducing cardiac regeneration. Nature. 2012 492:376-81.

24. Gabisonia K, Prosdocimo G, Aquaro GD, Carlucci L, Zentilin L, Secco I, et al. MicroRNA therapy stimulates uncontrolled cardiac repair after myocardial infarction in pigs. Nature. 2019;569:418-22.

25. Mills RJ, Parker BL, Quaife-Ryan GA, Voges HK, Needham EJ, Bornot A, et al Drug screening in human PSC-cardiac organoids identifies pro-proliferative compounds acting via the mevalonate pathway. Cell Stem Cell. 2019;24:895-907.e6.

\section{Commentary: Harnessing the regenerative potential of the human heart}

\author{
Amine Mazine, MD, MSc
}

Heart failure is a global epidemic, with an estimated prevalence of $>37.7$ million individuals worldwide. ${ }^{2}$ Although advances in primary prevention and treatment of heart failure have improved outcomes, there remains an unmet need for therapies that could restore cardiac function by replenishing heart muscle cells that are lost or damaged in the setting of heart failure. In recent years, regenerative medicine has emerged as a promising avenue to develop such therapies. Broadly speaking, efforts in the field of cardiovascular regenerative medicine can be categorized into 2 approaches. The first consists in the lineage-specific differentiation of human pluripotent stem cells (hPSCs) to generate cardiomyocytes for transplantation. The second consists in unlocking the endogenous regenerative potential of the human heart through "cardiac rejuvenation."

\footnotetext{
From the Division of Cardiovascular Surgery, University of Toronto, Toronto, Ontario, Canada.

Disclosures: Author has nothing to disclose with regard to commercial support.

Received for publication Dec 18, 2019; revisions received Dec 18, 2019; accepted for publication Dec 18, 2019; available ahead of print Jan 31, 2020.

Address for reprints: Amine Mazine, MD, MSc, Cardiovascular Surgery, Peter Munk Cardiac Centre, Toronto General Hospital, 200 Elizabeth St, Toronto, Ontario, Canada M5G2C4 (E-mail: amazine@gmail.com).

J Thorac Cardiovasc Surg 2020;159:2455-6

$0022-5223 / \$ 36.00$

Copyright (c) 2020 by The American Association for Thoracic Surgery

https://doi.org/10.1016/j.jtcvs.2019.12.096
}

day 1
Regeneration of the neonatal mouse myocardium
following apical resection.

CENTRAL MESSAGE
Understanding the hormonal
mechanisms that control cardiac
regenerative capacity is essential
to develop cardiac rejuvenation
and stem-cell based therapies.

Support for this second approach was bolstered by the seminal work of Sadek and Porello, ${ }^{1}$ who demonstrated that during the neonatal period, the mammalian heart retains significant regenerative capacity but that this potential is lost shortly after birth (Figure 1). Proponents of the cell-free "cardiac rejuvenation" approach propose to use small molecules, recombinant proteins, or gene therapies to reprogram mature cardiomyocytes back to their "immature" state to restore their proliferative potential. Such a strategy requires a thorough understanding of the biological mechanisms underpinning human cardiac regeneration.

In this issue of the Journal, Sadek and Porrello ${ }^{3}$ discuss recent evidence on the role of thyroid hormone signaling in modulating the regenerative capacity of the heart. Their article focuses on a recently published study by Hirose 
and colleages, ${ }^{4}$ which demonstrated an inverse correlation between cardiac regenerative potential and thyroid hormone levels. Hirose and colleagues further introduced a novel evolutionary paradigm whereby the loss of cardiac regenerative potential is ontogenetically and phylogenetically associated with thyroid hormonedependent acquisition of endothermy, thereby highlighting the evolutionary advantage of shutting down regenerative capacity after birth.

While Sadek and Porrello highlight the relevance of these findings to the field of "cardiac rejuvenation," the authors also point out some important limitations that cast a doubt on the viability of thyroid hormone signaling as a therapeutic target for cardiac regeneration. The most important of these limitations is the fact that despite promising proof-of-concept studies in model organisms, there is currently no convincing evidence demonstrating that acute modulation of thyroid hormone signaling in humans can promote cardiac regeneration following injury. Furthermore, the interplay of thyroid hormone signaling with other triggers of cardiac maturation-such as a highly oxidative metabolic environment ${ }^{5,6}$-remains to be elucidated.

While Sadek and Porrello focus on "cardiac rejuvenation," the findings they describe also have direct relevance to the field of hPSC-based cardiac cell therapy. Indeed, preclinical studies in large animal models have shown that hPSC-derived cardiomyocytes can stably engraft and electromechanically integrate with host myocardium. However, these grafts consistently induce ventricular tachyarrhythmias. ${ }^{7}$ It is believed that these ventricular tachyarrhythmias are driven, at least in part, by the immature nature of the transplanted cardiomyocytes, which correspond to the early fetal stage. ${ }^{8}$ As a result, considerable effort is being deployed to develop protocols that promote the maturation of hPSC-derived cardiomyocytes. Studies like the one by Hirose and colleagues offer valuable insight that can help guide the development of such protocols. In fact, multiple studies have already demonstrated that treatment with triiodothyronine can promote the ultrastructural,

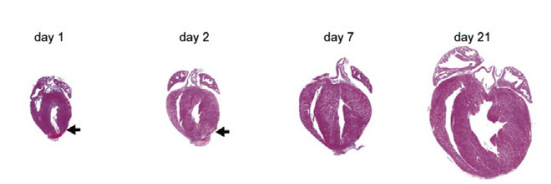

FIGURE 1. Regeneration of the neonatal mouse myocardium following apical resection. ${ }^{1}$

electrophysiological, and metabolic maturation of hPSCderived cardiomyocytes. ${ }^{9-11}$ Whether transplantation of more mature cardiomyocytes will result in decreased arrhythmia burden is the object of active investigation.

\section{References}

1. Porrello ER, Mahmoud AI, Simpson E, Hill JA, Richardson JA, Olson EN, et al. Transient regenerative potential of the neonatal mouse heart. Science. 2011;331: 1078-80.

2. Ziaeian B, Fonarow GC. Epidemiology and aetiology of heart failure. Nat Rev Cardiol. 2016;13:368-78.

3. Sadek HA, Porrello ER. Neonatal heart regeneration: moving from phenomenology to regenerative medicine. J Thorac Cardiovasc Surg. 2020; 159:2451-5.

4. Hirose K, Payumo AY, Cutie S, Hoang A, Zhang H, Guyot R, et al. Evidence for hormonal control of heart regenerative capacity during endothermy acquisition. Science. 2019;364:184-8.

5. Nakada Y, Canseco DC, Thet S, Abdisalaam S, Asaithamby A, Santos CX, et al. Hypoxia induces heart regeneration in adult mice. Nature. 2017;541:222-7.

6. Puente BN, Kimura W, Muralidhar SA, Moon J, Amatruda JF, Phelps KL, et al. The oxygen-rich postnatal environment induces cardiomyocyte cell-cycle arrest through DNA damage response. Cell. 2014;157:565-79.

7. Romagnuolo R, Masoudpour H, Porta-Sanchez A, Qiang B, Barry J, Laskary A, et al. Human embryonic stem cell-derived cardiomyocytes regenerate the infarcted pig heart but induce ventricular tachyarrhythmias. Stem Cell Rep. 2019;12:967-81.

8. Uosaki H, Cahan P, Lee DI, Wang S, Miyamoto M, Fernandez L, et al. Transcriptional landscape of cardiomyocyte maturation. Cell Rep. 2015;13: 1705-16.

9. Chattergoon NN, Giraud GD, Louey S, Stork P, Fowden AL, Thornburg KL. Thyroid hormone drives fetal cardiomyocyte maturation. FASEB J. 2012;26: 397-408.

10. Lee YK, Ng KM, Chan YC, Lai WH, Au KW, Ho CY, et al. Triiodothyronine promotes cardiac differentiation and maturation of embryonic stem cells via the classical genomic pathway. Mol Endocrinol. 2010;24:1728-36.

11. Yang X, Rodriguez M, Pabon L, Fischer KA, Reinecke H, Regnier M, et al. Tri-iodo-1-thyronine promotes the maturation of human cardiomyocytesderived from induced pluripotent stem cells. J Mol Cell Cardiol. 2014;72: 296-304. 